\title{
Evaluation of Caspase-9b and PP2Aca2 as potential biomarkers for chronic lymphocytic leukemia
}

Leticia Domínguez-Berrocal ${ }^{1}$, Xiguang Zhang ${ }^{2}$, Jean Marc Zini ${ }^{3}$, Jesús Fominaya ${ }^{2}$, Angelita Rebollo² and Jerónimo Bravo ${ }^{1 *}$

\begin{abstract}
Background: Disruption of alternative splicing in apoptotic factors has been associated to chronic lymphocytic leukemia among other cancers and hematological malignancies. The proapoptotic proteins Caspase-9 and PP2Aca are functionally related in a direct interaction, which constitutes a promising target for cancer therapy. Both proteins present aberrant mRNA splicing variants that are antiapoptotic (Caspase-9b) and catalytically inactive (PP2Aca2), respectively.

Results: In this work we have analyzed the relative abundance of the aberrant spliced forms Caspase-9b and PP2Aca2 in several cell lines and chronic lymphocytic leukemia patients and correlated it with several parameters of the disease. Despite $40 \%$ of the patients presented Caspase-9b dysregulation, there was no direct association between alterations in Caspase-9b relative abundance and the parameters analyzed in medical records. More importantly, PP2Aca2 dysregulation was observed in $88 \%$ of CLL patients and was related with advanced stages of the malignancy.

Conclusions: Caspase-9b dysregulation seemed to be associated with the disease, although the differences between healthy donors and CLL patients were not statistically significant. However, PP2Aca2 dysregulation was significantly different between healthy donors and CLL patients and correlated with Binet B and C stages; therefore, we propose the use of PP2Aca2 dysregulation as a potential biomarker for advanced stages of chronic lymphocytic leukemia.
\end{abstract}

Keywords: Caspase-9, Caspase-9b, PP2Aca, PP2Aca2, Chronic lymphocytic leukemia, Alternative splicing, Biomarker

\section{Introduction}

Chronic lymphocytic leukemia (CLL) is the most common B-cell malignancy in Caucasian aging adults, rarely younger than 50 years old [1]. Disruption of alternative splicing in many apoptotic factors is related to hematological malignancies and cancer, as CLL [2-6]. Abnormally expressed splicing factors in tumor cells induce the production of mRNA isoforms that are nonexistent or less abundant in normal cells, thus contributing to cancer development, tumor progression, different response to therapy and chemorefractoriness $[7,8]$.

\footnotetext{
* Correspondence: jbravo@ibv.csic.es

'Instituto de Biomedicina de Valencia, Consejo Superior de Investigaciones

Científicas (IBV-CSIC), c/ Jaime Roig 11, 46010 Valencia, Spain

Full list of author information is available at the end of the article
}

Caspase-9 is a key point in the apoptotic signal transduction. The expression of its mRNA spliced variant Caspase9b, lacking exons 3 to 6, inhibits apoptosis in a dominantnegative manner [9], which may establish a threshold to regulate Caspase-9 activation and prevent undesired apoptosis [10]. Caspase-9b is dysregulated in astrocytoma [11] and in several subtypes of non-small-cell lung cancer (NSCLC). Moreover, its overexpression was responsible of maintaining the tumorigenic capacity of NSCLC cells and made cells resistant to erlotinib [12]. Targeting the alternative splicing of Caspase-9 sensitized NSCLC cells to chemotherapies, increasing their efficiency and limiting their toxic side-effects [13].

The direct interaction between Caspase-9 and PP2Ac $\alpha$ has been previously described [14]. PP2A is one of the 
major Ser/Thr phosphatases, whose dysregulation is associated with multiple cancers among other functions [15]. A catalytically inactive aberrant isoform of PP2A catalytic C subunit, PP2Aca2, has been reported, missing exon 5, which is close to the active site. PP2Ac 2 has only been observed overexpressed in peripheral blood mononuclear cells (PBMC) under starvation conditions but the ratio PP2Ac $\alpha$ PP2Ac $\alpha 2$ was reestablished once they were transferred to culture medium. When analyzed in cell lines, PP2Ac 2 was present either as mRNA or as protein but at almost undetectable levels [16].

The aim of the present work was to study the expression ratios Caspase-9: Caspase-9b and PP2Aca:P$\mathrm{P} 2 \mathrm{Ac} \alpha 2$ in cell lines and more importantly in healthy donors and CLL patients to evaluate their association with the disease.

\section{Material and methods}

\section{Cell lines culture}

HeLa cells were cultured in DMEM $+10 \%$ FBS, Daudi and Jurkat cells in RPMI $1640+10 \%$ FBS and SH-SY5Y in DMEM F12 + 10 \% FBS, 1 \% Glutamine and $1 \%$ Hepes $1 \mathrm{M}$. All cell lines were grown at $37{ }^{\circ} \mathrm{C}$ and $5 \% \mathrm{CO}_{2}$ and underwent passage three times a week.

\section{B cells isolation}

Fresh blood from healthy donors was obtained from the Établissement français du sang. CLL samples were obtained from the Hematology Department of Saint Louis hospital (Paris). PBMC were isolated by Ficoll gradient centrifugation for $20 \mathrm{~min}$ at $2300 \mathrm{rpm}$, they were collected and washed twice with PBS. B cells were isolated using DynaI negative isolation kit (Invitrogen), reaching around $98 \%$ purity.

\section{Conventional PCR and Real Time PCR}

Total RNA was extracted with TRIzol ${ }^{\circ}$ (Life Technologies), cDNA was obtained performing RT-PCR using High Capacity cDNA Reverse Transcription Kit (Applied Biosystems) and conventional PCR was set up with Kapa HiFi DNA polymerase (Kapa Biosystems) at $95{ }^{\circ} \mathrm{C}-3$, 30 cycles of $98^{\circ} \mathrm{C}-20^{\prime \prime}, 55^{\circ} \mathrm{C}-20^{\prime \prime}, 72{ }^{\circ} \mathrm{C}-1$ '30" and a final extension of $72{ }^{\circ} \mathrm{C}-5$ '. The primers used were FWD: 5'-ATGGACGAAGCGGATCGG-3' and REV: 5'-TTATGATGTTTTAAAGAAAAGTT-3' for Caspase-9 and FWD 5'GACGAGAAGGTGTTCACCAA-3' and REV 5'-TTACAGGAAGTAGTCTGGGGTAC-3' for PP2Aca.

Real Time PCR was performed using TaqMan PCR Mastermix in a 7500 Fast Real Time Applied Biosystems device. Caspase9 and PP2Ac $\alpha$ probes corresponded to Hs00154261_m1 and Hs01003394_mH Life Technologies references. Caspase9b probe was previously described [17] and PP2Ac $\alpha 2$ primers and probe were designed: 5'-CAAGAAGTTCCCCATGAGGGATATA-3' (forward), 5'-CAACGATAACAATAGTTTGGAGCACT3' (reverse) and 5'-CGTTACTACATTCCGGTCATGGCACCA-3' (probe). GAPDH was used as housekeeping reference gene (Hs99999905_m1, Life Technologies). Data analysis of relative expression was calculated following the $2_{\mathrm{T}}^{-\Delta \Delta \mathrm{C}}$ method [18]. Differences between healthy donors and CLL patients were statistically evaluated with Student's $t$ test and with a Two-way ANOVA with replication with a significance level of $P<0.005$.

\section{Results and discussion}

\section{Caspase-9b and PP2Aca2 expression in cell lines}

Among the cell lines analyzed, derived from different oncologic malignancies, all of them showed a healthy ratio of Caspase-9b relative abundance in PCR and Real Time PCR assays (Fig. 1a and b). As established by Shultz et al. [19], the criteria used to classify Caspase-9b
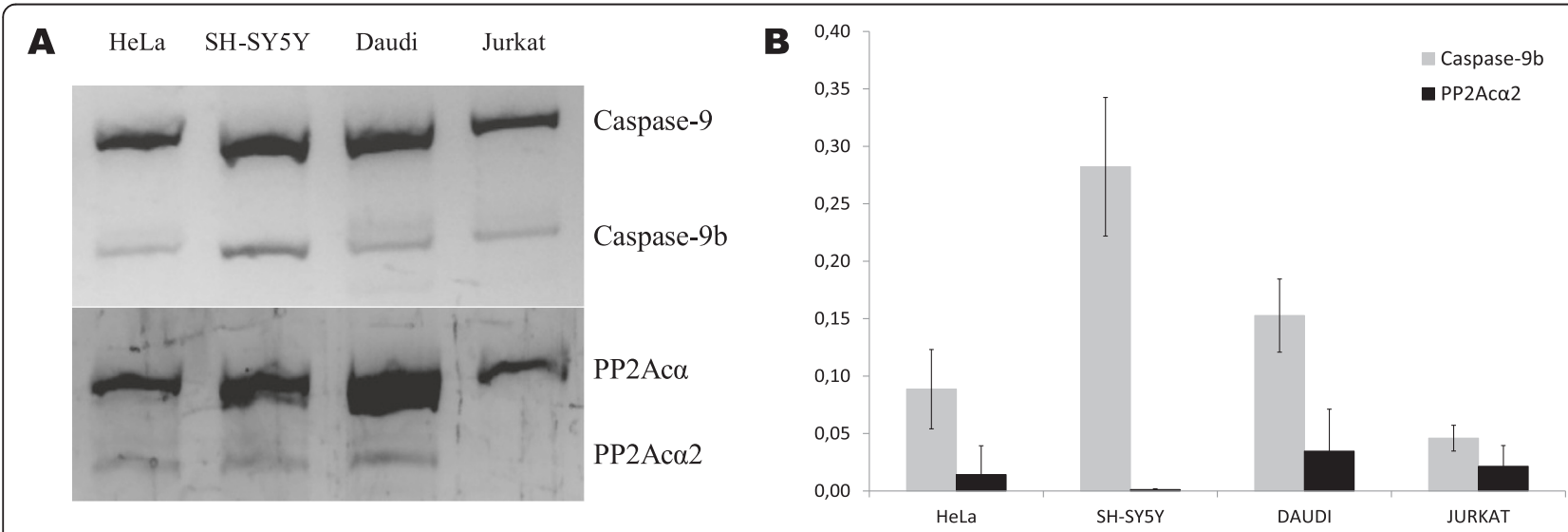

Fig. 1 Analysis of Caspase-9b and PP2Aca2 in several cancer cell lines. a. Conventional PCR analysis of cancer cell lines showing Caspase-9 and PP2Aca full length and spliced variants expression. b. Real Time PCR of cancer cell lines. Caspase-9b and PP2Aca2 relative abundance is represented in the graph and normalized with respect to Caspase-9 and PP2Aca respectively, considered as 1 
levels were: normal (Caspase-9: Caspase-9b mRNA ratio $\geq 3.3)$, moderately dysregulated $(3.3>\mathrm{X}>2.2)$ and highly dysregulated $(\leq 2.2)$. Following the criteria that we established for CLL patients as described below, cell lines possessed PP2Ac $\alpha 2$ mRNA levels corresponding to healthy state, obtaining very low values in Real Time PCR and a faint band in conventional PCR, when detected (Fig. 1a and b). These results suggest that Caspase-9b or PP2Ac 2 dysregulation wouldn't be characteristic of the analyzed cell lines, which prompted us to consider the approach of using samples from CLL patients instead of insisting with other established cell lines. Patients samples of these pathologies should be analyzed to confirm cell lines data; nevertheless in previous studies Caspase-9b dysregulation has been observed in the same extent in NSCLC cells and patients [12].

\section{Caspase-9b and PP2Aca2 expression in healthy donors and CLL patients}

Conventional PCR showed that Caspase-9b was slightly expressed in healthy donors, while CLL patients showed a moderate overexpression. Healthy donors showed no detectable or very low expression of PP2Aca2, but the majority of CLL patients presented from moderate to high overexpression of the aberrant form (Fig. 2a).

A cohort of 24 healthy donors and 25 CLL patients (15 men and 10 women) was analyzed by Real Time PCR. Figure 2b summarizes Caspase-9b and PP2Ac 2 expression in CLL patients. $80 \%$ of healthy donors showed Caspase-9b normal ratio and the rest were slightly over healthy values (Fig. 2c). Unlike in NSCLC [19], where $36 \%$ of the patients were moderately dysregulated and $42 \%$ were highly dysregulated, in CLL only $40 \%$ of the patients had some alteration in Caspase-9b expression (Fig. 2d), although the highly dysregulated also overcame the moderate percentage ( $28 \%$ versus $12 \%$ ).

According to Shultz et al.[19] criteria for Caspase$9 \mathrm{~b}$ dysregulation, $80 \%$ of the healthy donors that we analyzed fitted into normal values for Caspase-9b. However, PP2Ac 22 was expressed in healthy donors in a PP2Ac $\alpha$ :PP2Ac 2 ratio from negligible values up to 1.27 in $80 \%$ of the samples (Fig. 2c). Therefore, we formulated classification criteria that would fit a similar percentage of healthy donors in each category as the ones described by Schultz for Caspase9b. We established a mRNA ratio PP2Ac $\alpha$ :PP2Ac $2 \geq$ 1.33 for healthy expression, $0.67<\mathrm{X}<1.33$ for moderately dysregulated and $\leq 0.67$ for highly dysregulated. According to this, $88 \%$ of CLL patients analyzed had overexpression levels of PP2Ac 2 (Figs. 2b and d). The efficacy of the use of PP2Ac 2 as a CLL biomarker and the applicability of our criteria was validated with the calculation of several clinical parameters. The prevalence of the disease in the whole cohort was $51.02 \%$ and the use of PP2Ac 2 as a biomarker presented a sensitivity of $78.57 \%$, a specificity of $85.71 \%$, a positive predictive value of $88 \%$ and a negative predictive value of $75 \%$. According to these results, the detection of a PP2Aca2 overexpression in a patient will allow to diagnose CLL in a $78.57 \%$ of the cases. The specificity of this biomarker assures that $85.71 \%$ of the patients without a dysregulation of PP2Ac 2 don't present the disease and only a $14.29 \%$ would be diagnosed as false positives.

Gathering the data of relative abundance of spliced variants with the medical records available $[20,21]$ (Table 1), we couldn't establish a direct correlation between the dysregulation in Caspase-9b and any of the disease parameters analyzed, but we don't exclude that it may be related to other features of this malignancy. However, this dysregulation in $40 \%$ of CLL patients makes us consider it as a manifestation of the disease and it could be a potential biomarker in some extent, although the differences between healthy donors and CLL patients were not statistically significant according to Student's $t$ test $(P=0.1878)$. Interestingly, all individuals classified in the medical records as B or C Binet score [20] presented highly dysregulated PP2Ac 2 , being the only patient with score $\mathrm{C}$ the one with the highest PP2Aca2 levels. Among A score patients, PP2Ac 2 levels from normal to highly dysregulated were found. In this case, the differences between healthy donors and CLL patients for PP2Ac 2 relative abundance were statistically significant $(P<0.005, P=0.0024)$. A two-way ANOVA with replication was also performed between healthy donors and CLL patients 1-24 for Caspase-9b and PP2Ac 2 relative abundance. The differences between healthy donors and CLL patients were significant $(P<$ $0.0005)$ and also between Caspase-9b and PP2Ac 2 $(P<0.00005)$. The interaction $\mathrm{P}$-value $(P<0.005)$ suggested that the variables Caspase-9b and PP2Ac $\alpha 2$ are different depending on the level of the other variable respectively. The distribution of Caspase-9b and PP2Aca2 relative abundance in the healthy donors and CLL patients populations was represented in Fig. 3. Although more extensive studies should be performed to confirm these data, we have promising evidences that suggest the importance of PP2Ac 2 in the course of CLL. For the first time, the aberrant spliced variant PP2Ac 22 has been related with a pathological state, suggesting its implication in the disease and a possible function for a protein that remains known as inactive.

Several markers as CD38, ZAP-70 and $\operatorname{IgV}_{\mathrm{H}}$ mutation status among others have been implemented as CLL 


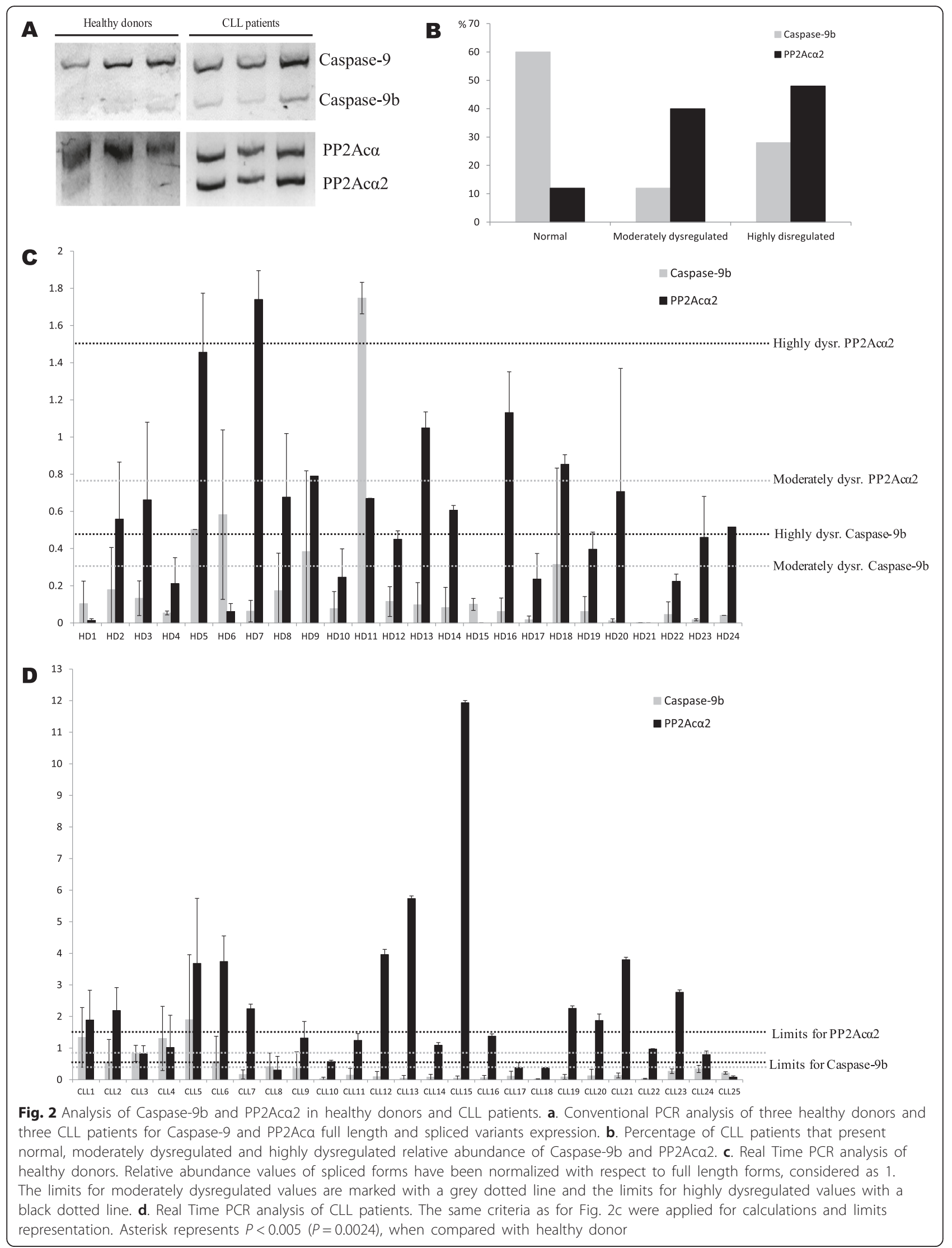


Table 1 Available medical records of the CLL patients analyzed

\begin{tabular}{|c|c|c|c|c|c|c|c|c|c|}
\hline Patient & Age at diagnosis & Previous treatments & White blood cells & Hemoglobin & Platelets & Matutes score & Binet score & Caspase-9b & PP2Aca2 \\
\hline CLL15 & 71 & NO & 100000 & 10.2 & 86 & 4 & C & 0.05 & 11.93 \\
\hline CLL13 & 56 & NO & 97000 & 11.7 & 230 & 5 & B & 0.05 & 5.73 \\
\hline CLL12 & 63 & NO & 85000 & 12.7 & 116 & 5 & B & 0.10 & 3.96 \\
\hline CLL21 & 64 & NO & 110000 & 9.8 & 95 & 5 & B & 0.13 & 3.80 \\
\hline CLL6 & 82 & NO & 28000 & 10.6 & 206 & 5 & B & 0.57 & 3.74 \\
\hline CLL19 & 60 & YES & 230000 & 12.5 & 90 & 5 & B & 0.09 & 2.26 \\
\hline CLL5 & 72 & NO & 200000 & 12.9 & 92 & 5 & A & 1.90 & 3.68 \\
\hline CLL2 & 78 & NO & 100000 & 12.3 & 223 & 4 & A & 0.55 & 2.19 \\
\hline CLL1 & 50 & NO & 130000 & 10.9 & 189 & 5 & A & 1.34 & 1.89 \\
\hline CLL20 & 68 & NO & 87000 & 10.6 & 120 & 5 & A & 0.12 & 1.87 \\
\hline CLL16 & 43 & NO & 44000 & 15.0 & 210 & 5 & A & 0.06 & 1.38 \\
\hline CLL11 & 75 & NO & 25000 & 14.2 & 186 & 4 & A & 0.14 & 1.24 \\
\hline CLL4 & 72 & NO & 27000 & 14.6 & 250 & 5 & A & 1.30 & 1.02 \\
\hline CLL3 & 68 & NO & 80000 & 13.1 & 188 & 5 & A & 0.83 & 0.82 \\
\hline CLL17 & 87 & NO & 140000 & 10.1 & 66 & 5 & $A$ & 0.11 & 0.38 \\
\hline
\end{tabular}

Age, treatment with fludarabin (in the case of CLL19), hematological parameters and Matutes score (that confirms these patients as CLL) registered in medical records for some of the patients analyzed are compiled in this table. Binet score B and C, indicating advanced stages of the disease, are highlighted in bold. Normalized values of relative abundance of Caspase-9b and PP2Aca2 have been added to the table

progression and diagnosis predictors not without certain controversy [22-24]; therefore we propose also the use of PP2Ac 2 high dysregulation as a potential CLL biomarker associated to severe stages of the disease.

Disruption of the PP2Ac $\alpha$ PP2Ac $\alpha 2$ ratio in CLL patients may also alter the equilibrium of Caspase-9/PP2Ac $\alpha$ interaction, giving rise to aberrant Caspase-9/PP2Ac $\alpha 2$ complexes. Interestingly, we have previously reported a bifunctional peptide termed DPT-C9h, capable of dissociating Caspase-9/PP2Ac $\alpha$ complex [14]. Given that Caspase9 binding site is present in both PP2Ac $\alpha$ and PP2Ac $\alpha 2$, DPT-C9h may also interfere in the hypothetical Caspase9/PP2Ac 2 interaction, contributing to a possible modulation of the DPT-C9h mechanism of action and differential treatment response [14].
This bifunctional peptide induced apoptosis in CLL B cells without affecting healthy B cells nor the rest of peripheral blood mononuclear cells [25]. The bifunctional peptide DPT-C9h was also capable of inducing apoptosis in several cancer cell lines and in tumor xenograft models with treatment response in a different extent, which may be related to the relative abundance of PP2Ac 2 in the cell lines and patients tested [14]. Further experiments will be performed to shed light on the role of PP2Aca2 in CLL and the hypothetical differential response to DPT-C9h depending on the level of PP2Ac 2 dysregulation.

Caspase-9b has been related to disease state in astrocytoma [11] and to play an important role in NSCLC treatment response [12]. Our results provide first evidences for

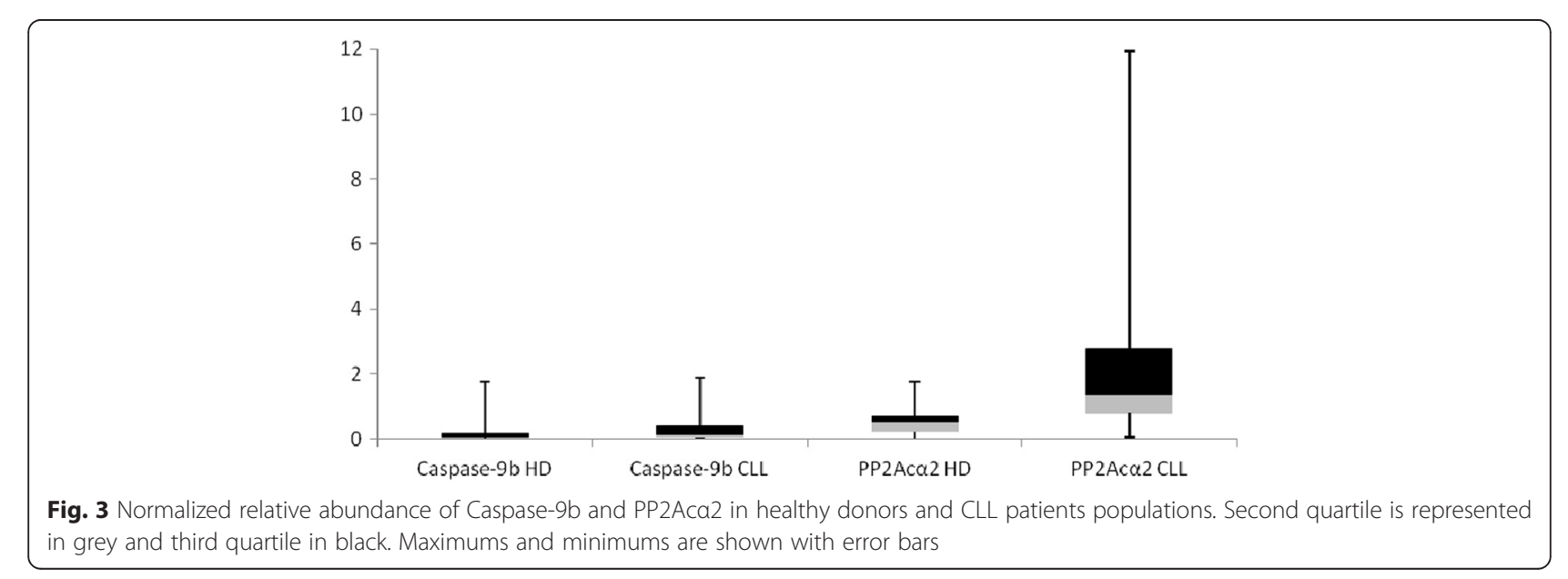


the presence of aberrant PP2Ac $\alpha / \mathrm{PP} 2 \mathrm{Ac} \alpha 2$ ratios in CLL advanced stage patients. Therefore, the dysregulation of the splicing variants of the association Caspase-9/PP2Ac $\alpha$ is emerging as a valuable tool as biomarkers for prognosis in cancers that present aberrant expression of Caspase-9b or PP2Ac 2 spliced variants. Further studies will need to be performed to evaluate Caspase-9/Caspase-9b and $\mathrm{PP} 2 \mathrm{Ac} \alpha / \mathrm{PP} 2 \mathrm{Ac} \alpha 2$ ratios in other types of cancer and their possible application as biomarkers.

\section{Ethics approval and consent to participate}

The experiments with human samples included in this work were performed in accordance with the Declaration of Helsinki. No ethics committee approval was required for these experiments. Written informed consent was obtained from all patients.

\begin{abstract}
Abbreviations
CLL: chronic lymphocytic leukemia; DMEM: Dulbecco's modified Eagle medium; DPT: drug phosphatase technology; FBS: fetal bovine serum; NSCLC: non-small-cell lung cancer; PBMC: peripheral blood mononuclear cells; RT-PCR: reverse transcription polymerase chain reaction.
\end{abstract}

\section{Competing interests}

The authors declare that they have no competing interests.

\begin{abstract}
Authors' contributions
LD-B designed experiments and wrote the paper; JMZ and AR provided samples and medical records; LD-B and XZ performed experiments; LD-B, JF, $A R$ and JB analyzed results and revised the manuscript. All authors read and approved the final manuscript.
\end{abstract}

\section{Funding}

This work was supported by grants from the Ministerio de Economía y Competitividad (Spain) SAF2012-31405, SAF2015-67077-R and the Generalitat Valenciana (Spain) (PROMETEO/2012/061) for sample preparation, experiment performance, data collection and analysis and manuscript writing and INSERM (France) for sample extraction, preparation and transport. We acknowledge support of the publication fee by the CSIC Open Access Publication Support Initiative through its Unit of Information Resources for Research (URICI).

\begin{abstract}
Author details
'Instituto de Biomedicina de Valencia, Consejo Superior de Investigaciones Científicas (IBV-CSIC), c/ Jaime Roig 11, 46010 Valencia, Spain. ${ }^{2}$ Institut National de la Santé et de la Recherche Médicale (INSERM), U1135, 83, Université Pierre et Marie Curie, 91 bd de l'Hôpital, 75013 Paris, France. ${ }^{3}$ Assistance Publique - Hôpitaux de Paris (AP-HP), Hôpital Saint Louis, 1 avenue Claude Vellefaux, 75010 Paris, France.
\end{abstract}

Received: 17 February 2016 Accepted: 26 April 2016

Published online: 04 May 2016

\section{References}

1. Rozman C, Montserrat E. Chronic lymphocytic leukemia. N Engl J Med. 1995;333:1052-7.

2. Venables JP. Unbalanced alternative splicing and its significance in cancer. BioEssays. 2006;28:378-86.

3. Makishima H, Visconte V, Sakaguchi H, Jankowska AM, Kar SA, Jerez A, Przychodzen B, Bupathi M, Guinta K, Afable MG, Sekeres MA, Padgett RA, Tiu RV, Maciejewski JP: Mutations in the spliceosome machinery, a novel and ubiquitous pathway in leukemogenesis. Blood. 2012;119:3203-10.

4. Klein A, Miera O, Bauer O, Golfier S, Schriever F. Chemosensitivity of B cell chronic lymphocytic leukemia and correlated expression of proteins regulating apoptosis, cell cycle and DNA repair. Leukemia. 2000;14:40-6.
5. Ringshausen I, Schneller F, Bogner C, Hipp S, Duyster J, Peschel C, Decker T: Constitutively activated phosphatidylinositol-3 kinase ( $\mathrm{Pl}-3 \mathrm{~K}$ ) is involved in the defect of apoptosis in B-CLL: Association with protein kinase C $\delta$. Blood. 2002;100:3741-8.

6. Packham G, Stevenson FK. Bodyguards and assassins: Bcl-2 family proteins and apoptosis control in chronic lymphocytic leukaemia. Immunology. 2005;114:441-9.

7. Sampath J, Long PR, Shepard RL, Xia X, Devanarayan V, Sandusky GE, Perry WL, Dantzig AH, Williamson M, Rolfe M, Moore RE: Human SPF45, a splicing factor, has limited expression in normal tissues, is overexpressed in many tumors, and can confer a multidrug-resistant phenotype to cells. Am J Pathol. 2003;163:1781-90.

8. Wang L, Lawrence MS, Wan Y, Stojanov P, Sougnez C, Stevenson K, Werner L, Sivachenko A, DeLuca DS, Zhang L, Zhang W, Vartanov AR, Fernandes SM, Goldstein NR, Folco EG, Cibulskis K, Tesar B, Sievers QL, Shefler E, Gabriel S, Hacohen N, Reed R, Meyerson M, Golub TR, Lander ES, Neuberg D, Brown JR, Getz G, Wu CJ. SF3B1 and other novel cancer genes in chronic lymphocytic leukemia. N Engl J Med. 2011;365:2497-506.

9. Seol DW, Billiar TR. A caspase-9 variant missing the catalytic site is an endogenous inhibitor of apoptosis. J Biol Chem. 1999;274:2072-6.

10. Srinivasula SM, Ahmad M, Guo Y, Zhan Y, Lazebnik Y, Fernandes-Alnemri T, Alnemri ES: Identification of an endogenous dominant-negative short isoform of caspase-9 that can regulate apoptosis. Cancer Res. 1999;59:999-1002.

11. Waltereit R, Weller M. The role of caspases 9 and 9-short (9S) in death ligand- and drug-induced apoptosis in human astrocytoma cells. Mol Brain Res. 2002;106:42-9.

12. Shultz JC, Goehe RW, Murudkar CS, Wijesinghe DS, Mayton EK, Massiello A, Hawkins AJ, Mukerjee P, Pinkerman RL, Park MA, Chalfant CE. SRSF1 regulates the alternative splicing of caspase 9 via a novel intronic splicing enhancer affecting the chemotherapeutic sensitivity of non-small cell lung cancer cells. Mol Cancer Res. 2011;9:889-900.

13. Shultz JC, Chalfant CE. Caspase 9b: a new target for therapy in non-smallcell lung cancer. Expert Rev Anticancer Ther. 2011;11:499-502.

14. Arrouss I, Nemati F, Roncal F, Wislez M, Dorgham K, Vallerand D, Rabbe N, Karboul N, Carlotti F, Bravo J, Mazier D, Decaudin D, Rebollo A: Specific targeting of Caspase-9/PP2A interaction as potential new anti-cancer therapy. PLoS One. 2013;8:e60816.

15. Lechward K, Awotunde OS, SwiąTek W, Muszyńska G. Protein phosphatase 2A: Variety of forms and diversity of functions. Acta Biochim Pol. 2001;48:921-33.

16. Migueleti DLS, Smetana JHC, Nunes HF, Kobarg J, Zanchin NIT. Identification and characterization of an alternatively spliced isoform of the human protein phosphatase 2A catalytic subunit. J Biol Chem. 2012;287:4853-62.

17. Vu NT, Park MA, Shultz JC, Goehe RW, Hoeferlin LA, Shultz MD, Smith SA, Lynch KW, Chalfant CE. HnRNP U enhances caspase-9 splicing and is modulated by AKT-dependent phosphorylation of hnRNP L. J Biol Chem. 2013;288:8575-84.

18. Livak KJ, Schmittgen TD. Analysis of relative gene expression data using realtime quantitative PCR and the 2- $\Delta \Delta C T$ method. Methods. 2001;25:402-8.

19. Shultz JC, Goehe RW, Wijesinghe DS, Murudkar C, Hawkins AJ, Shay JW, Minna JD, Chalfant CE:. Alternative splicing of caspase 9 is modulated by the phosphoinositide 3-kinase/Akt pathway via phosphorylation of SRp30a. Cancer Res. 2010;70:9185-96.

20. Binet JL, Auquier A, Dighiero G, Chastang C, Piguet $H$, Goasguen J, Vaugier G, Potron G, Colona P, Oberling F, Thomas M, Tchernia G, Jacquillat C, Boivin P, Lesty C, Duault MT, Monconduit M, Belabbes S, Gremy F. A new prognostic classification of chronic lymphocytic leukemia derived from a multivariate survival analysis. Cancer. 1981;48:198-206.

21. Matutes E, Owusu-Ankomah KA, Morilla RM, García Marco J, Houlihan A, Que $\mathrm{TH}$, Catovsky D: The immunological profile of B-cell disorders and proposal of a scoring system for the diagnosis of CLL. Leukemia. 1994;8:1640-5.

22. Rassenti LZ, Huynh L, Toy TL, Chen L, Keating MJ, Gribben JG, Neuberg DS, Flinn IW, Rai KR, Byrd JC, Kay NE, Greaves A, Weiss A, Kipps TJ. ZAP-70 compared with immunoglobulin heavy-chain gene mutation status as a predictor of disease progression in chronic lymphocytic leukemia. N Engl J Med. 2004;351:893-901.

23. Inamdar KV, Bueso-Ramos CE. Pathology of chronic lymphocytic leukemia: an update. Ann Diagn Pathol. 2007;11:363-89.

24. Matutes E, Wotherspoon A, Catovsky D. Differential diagnosis in chronic lymphocytic leukaemia. Best Pract Res Clin Haematol. 2007;20:367-84.

25. Arrouss I, Decaudin D, Choquet S, Azar N, Parizot C, Zini JM, Nemati F, Rebollo A: Cell penetrating peptides as a therapeutic strategy in chronic lymphocytic leukemia. Protein Pept Lett. 2015;22:539-46. 